\title{
$\mathfrak{S} \mathfrak{n} \mathfrak{b} \mathfrak{a} \mathfrak{l} \mathfrak{t}$
}

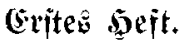

Die Brenzen zwifden Dialerei unb qiajtif unb bie (Gelese bes Reliefs. (Suibo şaut.) . . . . . . . . . . . . . . . Seite 1

Die Berwaltung ber હtabt Berlin. III. (ङogar Roeniug.). . . . . . . - 19

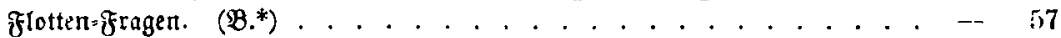

Bring Friebrid Sarl. (\$. Delbrïd.) . . . . . . . . . . . . . . . . . . 70

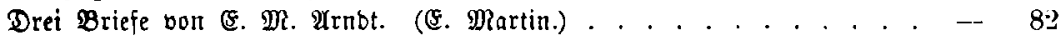

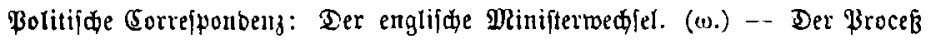

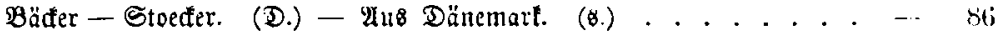

\section{3weites \$eft.}

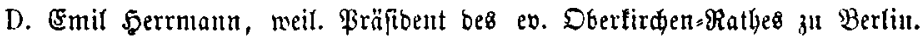
(D. Mogge.) . . . . . . . . . . . . . . . . . . -107

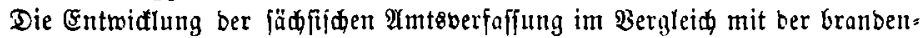

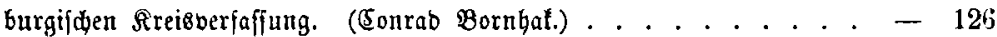

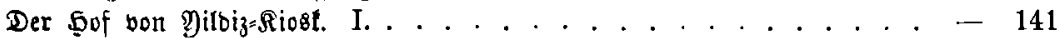

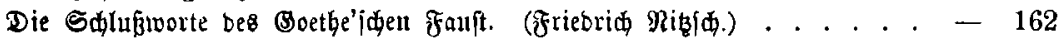

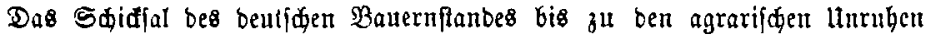
bes 15. und 16. Jabrguntert8. (Sart Rampredt.). . . . . . . .

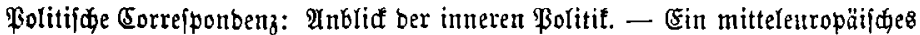

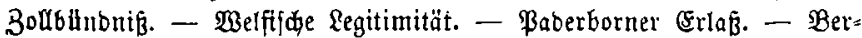

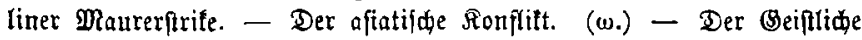

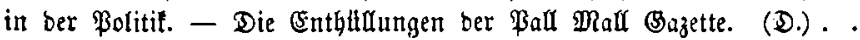

Notizen: Conftant v. Wurzbađ, Das biographifde Rerzifon bes Raiferthums Defterreid. . . . . . . . . . . . . . . . 209

\section{Drittes şeit.}

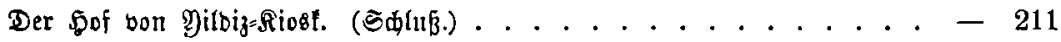

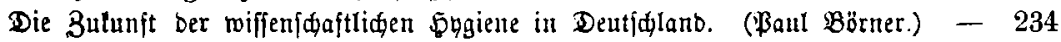
Der exfte Barbar auf bem römifden Raifertbronte. (Dtto Seeč.) . . . . - 267

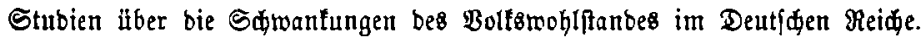

IV. (Dr. E. Philippi.) . . . . . . . . . . . - 301

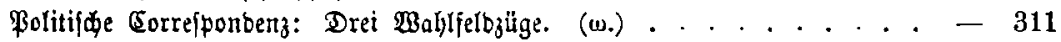
Rotizen: \$erzog Carl von $\mathfrak{B u ̈ t t e m b e r g}$ und ber Fürftenbunt von 1785 . -

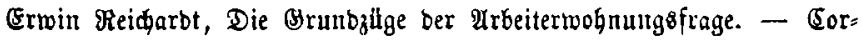
nelius Diaconoviф, Die romänifđe Revue. . . . . . . . . . . . - 326 


\section{Sierte: 5eft.}

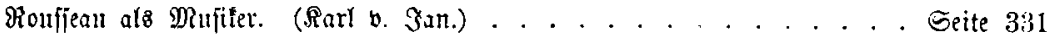

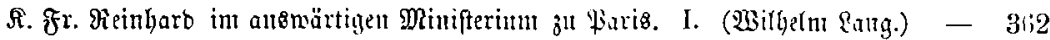

Briefe bon (E. M. Itrnot alt frranz \$egenijd. . . . . . . . . . . . - 3s9

Bolitije (Sorrefpontenz: Drei neltpolitifje Säntot. (w.) - Socialpolitijds:8.

(D.) - Die Benteraliqnote. (X.) . . . . . . . . . . . . - 403

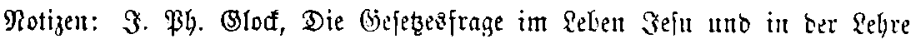

bes Paulus. - Dr. Beorg IIbler, Die Befdidte Ser erften Socialfoli= tijden Pltbeiterbemegung in Dentfdilate. - Mrfreb nou ber Eeven, Die

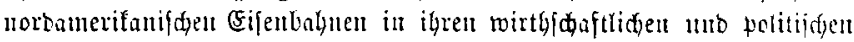

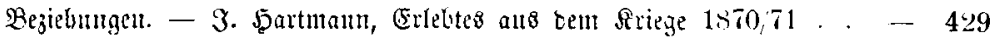

\section{જiuntes நejt.}

Die nenere Foridung über Maria Stuart. (Franz Bi(ject). . . . . . - 435,

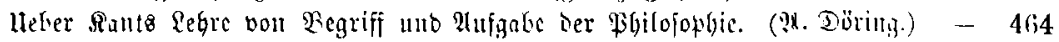

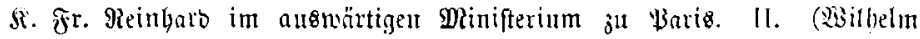

Qantg.) . . . . . . . . . . . . . . . . . - 442

Strafjuftiz uno Seffentidice Meinunz. (S. Pittelitiot.) . . . . . . . 499

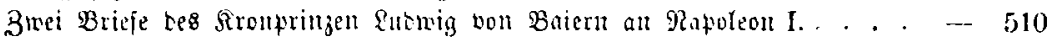

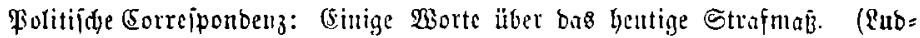
nig Fuld=Mainz.) -- Rarolinenfrage. - Balfanläuber. - Franzöitidje

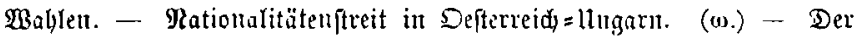

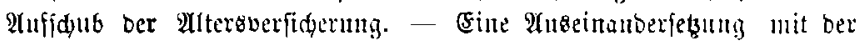
Rational=Zeitung. (D.) - Die Beneraljynobe. (X.) . . . . . . - 512 Peridtiguti. (Befeler) . . . . . . . . . . . . -540

\section{Eedjites sicft.}

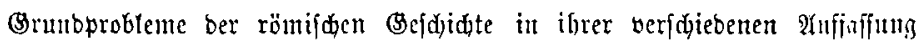
bei Ranfe uno Mommen. (\&ubrig Riể.) . . . . . . . . . - 543

Das Dresbener Rutberbentual und ber @itreit um ben äduten Sutherfopf

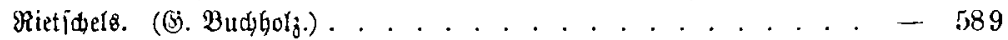

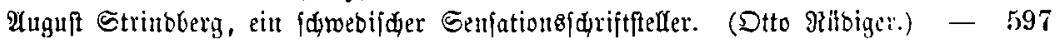

Ibolf Menzel. (Yulian Edmibt.) . . . . . . . . . . . . . . . - 628

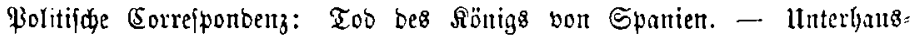
mablett in Englant. - Beginn ber uenen (Entroifflung in Franfreid. - Baltanlänber. (w.) - Der Meidgetat. (D.) - Die Rébenzfäbigs feit bes Reidgtuges. (D.) . . . . . . . . . . . . . . . .

Motizen: Boffert, Mürttemberg mo Ganffen. WGatther, \&utber im neneften

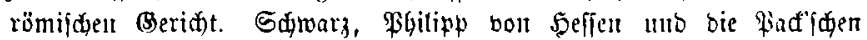

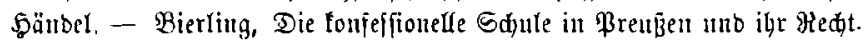

